\title{
Triple Bond Effect on Spacer and Acceptor of Phenothiazine Organic Dye Sensitizer for DSSCs: Quantum Chemical Investigation
}

\author{
Govindarasu R ${ }^{1}$, Subramanian M.K. ${ }^{1}$, Arunkumnar A ${ }^{2}$, Shanavas $\mathrm{S}^{2}$, ANBARASAN \\ PONNUSAMY MUNUSAMY², Tansir Ahamad ${ }^{3}$, and Saad M Alshehri ${ }^{3}$ \\ ${ }^{1}$ Thiruvalluvar Government Arts College \\ ${ }^{2}$ Periyar University \\ ${ }^{3}$ King Saud University
}

September 7, 2020

\begin{abstract}
In this work, a series of phenothiazine based organic dye sensitizers for dye-sensitized solar cells (DSSCs) have been designed and screened. The electron-donor as a phenothiazine, cyanoacrylic acid as an electron acceptor based on donor-acceptor (D-A) as reference dye SB. So as to enhance the triple bond effect on spacer and acceptor moieties has been investigated based on SB dye. The substituent effect of the spacer and electron acceptor on the absorption spectra and photovoltaic (PV) properties have been investigated by the combination of density functional theory (DFT) and time-dependent DFT (TDDFT) method approaches. Different exchange-correlation functionals have been initially evaluated in order to establish an accurate methodology for calculating the excited state energy of the SB dye. Consequently, TD-CAM-B3LYP method and $6-311++\mathrm{G}(\mathrm{d}, \mathrm{p})$ basis set have used been the comparison of experimental value. From the calculated results, concluded that the phenothiazine-4-((7-ethynylbenzo[c] $[1,2,5]$ thiadiazol-4-yl)ethynyl)benzoic acid (PT-EBTEBA) dye was strongly grouped for more red-shift and electrons injected into semiconductors effectively. It is expected to provide some theoretical guidance on designing photosensitive with new metal-free organic dyes for application in DSSCs yielding highly efficient performance.
\end{abstract}

\section{Hosted file}

Manuscript.doc available at https://authorea.com/users/356906/articles/479671-triple-bondeffect-on-spacer-and-acceptor-of-phenothiazine-organic-dye-sensitizer-for-dsscs-quantumchemical-investigation

\section{Hosted file}

Figures.doc available at https://authorea.com/users/356906/articles/479671-triple-bondeffect-on-spacer-and-acceptor-of-phenothiazine-organic-dye-sensitizer-for-dsscs-quantumchemical-investigation

\section{Hosted file}

Tables.doc available at https://authorea.com/users/356906/articles/479671-triple-bondeffect-on-spacer-and-acceptor-of-phenothiazine-organic-dye-sensitizer-for-dsscs-quantumchemical-investigation 